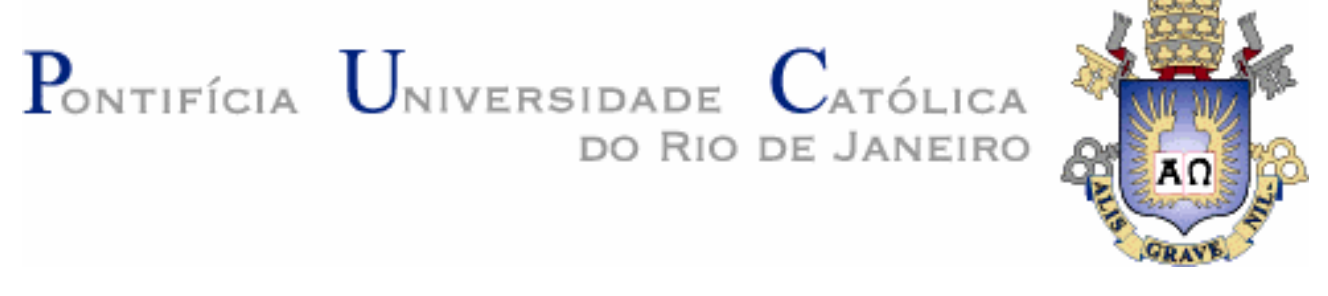

Herbet de Souza Cunha

\title{
Uso de Estratégias Orientadas a Metas para Modelagem de Requisitos de Segurança
}

\section{Dissertação de Mestrado}

Dissertação apresentada como requisito parcial para obtenção do grau de Mestre pelo Programa de Pósgraduação em Informática do Departamento de Informática da PUC-Rio.

Orientador: Prof. Julio César Sampaio do Prado Leite

Rio de Janeiro abril de 2007 


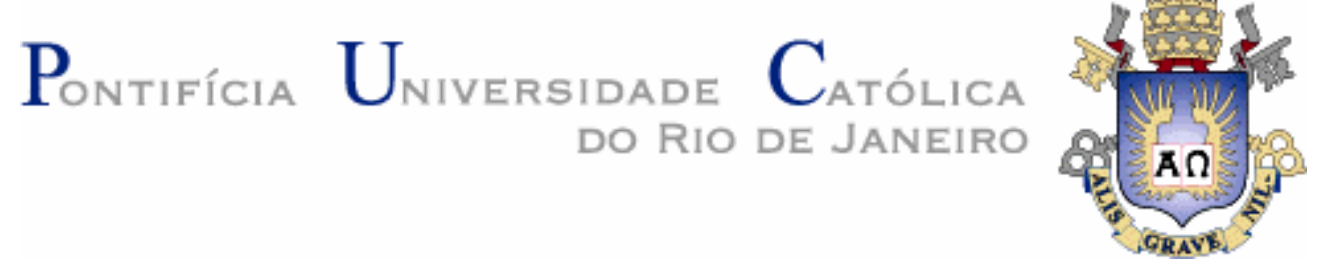

Herbet de Souza Cunha

\section{Uso de Estratégias Orientadas a Metas para Modelagem de Requisitos de \\ Segurança}

Dissertação apresentada como requisito parcial para obtenção do grau de Mestre pelo Programa de Pósgraduação em Informática do Departamento de Informática da PUC-Rio. Aprovada pela Comissão Examinadora abaixo assinada.

Prof. Julio Cesar Sampaio do Prado Leite
Orientador
Departamento de Informática - PUC-Rio

Prof. Arndt Von Staa Departamento de Informática - PUC-Rio

Profa. Vera Maria Benjamim Werneck Universidade do Estado do Rio de Janeiro - UERJ

Prof. José Eugênio Leal Coordenador Setorial do Centro Técnico Científico - PUC-Rio 
Todos os direitos reservados. É proibida a reprodução total ou parcial do trabalho sem autorização da universidade, do autor e do orientador.

\section{Herbet de Souza Cunha}

Graduou-se em Bacharelado em Ciências da Computação pela Universidade Federal de Pernambuco em agosto de 2000. Área de interesse acadêmico: Engenharia de Software, mais especificamente a sub-área de Engenharia de Requisitos. Atualmente é funcionário da área de Tecnologia da Informação da Petróleo Brasileiro SA (PETROBRAS) atuando na área de arquitetura de informações e metadados.

Ficha Catalográfica

Cunha, Herbet de Souza

Uso de estratégias orientadas a metas para modelagem de requisitos de segurança / Herbet de Souza Cunha; orientador: Julio César Sampaio do Prado Leite. - 2007.

148 f. : il. ; $30 \mathrm{~cm}$

Dissertação (Mestrado em Informática)Pontifícia Universidade Católica do Rio de Janeiro, Rio de Janeiro, 2007.

Inclui bibliografia

1. Informática - Teses. 2. Requisitos. 3. Segurança. I. Leite, Julio César Sampaio do Prado. II. Pontifícia Universidade Católica do Rio de Janeiro. Departamento de Informática. III. Título. 


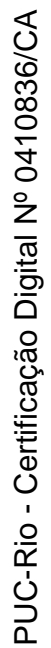

Para meus pais, Nalva e Milton, pelo incentivo e confiança. 


\section{Agradecimentos}

A Julio César Sampaio do Prado Leite pelas orientações e paciência.

A Antônio de Pádua Albuquerque Oliveira pela colaboração.

Aos amigos da Petrobras pelo incentivo e força.

A Petrobras pelo apoio. 


\section{Resumo}

Cunha, Herbet de Souza; Leite, Julio Cesar Sampaio do Prado. Uso de estratégias orientadas a metas para modelagem de requisitos de segurança. Rio de Janeiro, 2007. 148p. Dissertação de Mestrado Departamento de Informática, Pontifícia Universidade Católica do Rio de Janeiro

Adicionar requisitos de segurança às arquiteturas de software após elas terem sido construídas é uma tarefa bastante difícil. Conceitos de segurança devem permear todo o ciclo de desenvolvimento do software, desde a engenharia de requisitos, passando por desenho (design), implementação, testes e distribuição. Este trabalho apresenta uma abordagem para modelagem de requisitos de segurança, especialmente os requisitos de confidencialidade e consistência das informações, baseada em estratégias orientadas a metas, trazendo a questão da segurança para o início do ciclo de desenvolvimento de software. São apresentados também os resultados da aplicação desta abordagem em um estudo de caso.

\section{Palavras-chave}

Requisitos, Segurança 


\section{Abstract}

Cunha, Herbet de Souza; Leite, Julio Cesar Sampaio do Prado. Uso de estratégias orientadas a metas para modelagem de requisitos de segurança. Rio de Janeiro, 2007. 148p. Master degree thesis - Computer Science Department, Pontifícia Universidade Católica do Rio de Janeiro

Adding security requirements to software architectures after they are built is a hard work. Security concepts have to cross the whole software development cycle, from requirement engineering to deployment, passing by design, coding and test. This work presents an approach to security requirements modeling, mainly the information confidentiality and consistency, based on goal oriented strategies, bringing the security issues to the beginning of the software development cycle. It also presents the results of this approach in a case study.

\section{Keywords}

Requirements, Security. 


\section{Sumário}

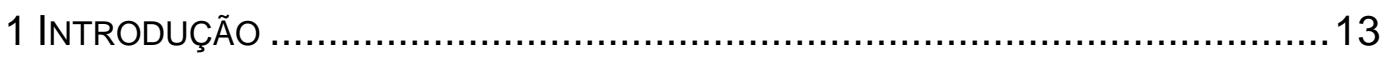

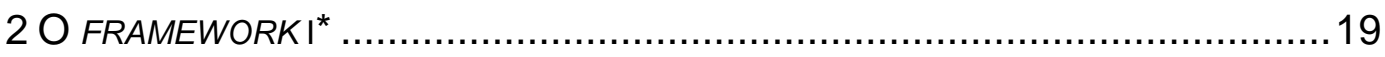

3 USO DE ESTRATÉGIAS ORIENTADAS A METAS .................................... 33

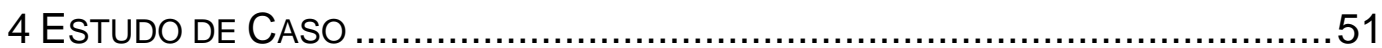

5 ANÁLISE dE TRABALHOS RELACIONADOS ..........................................129

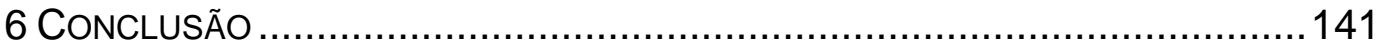

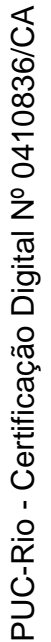

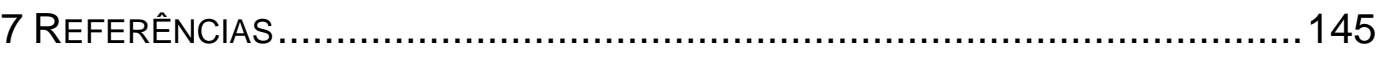




\section{Lista de Figuras}

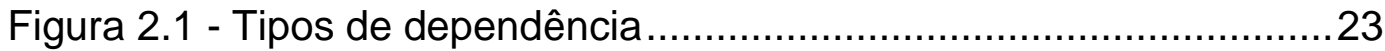

Figura 2.2 - Elos de decomposição de tarefa ...........................................24

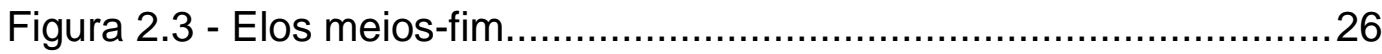

Figura 2.4 - Meta-modelo elaborado em UML para Strategic Actor (SA)

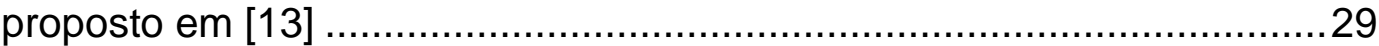

Figura 3.1 - Visão geral da Engenharia de Requisitos, adaptada de [30] 34

Figura 3.2 - Processo de definição de requisitos usando i* de Liu, Yu e

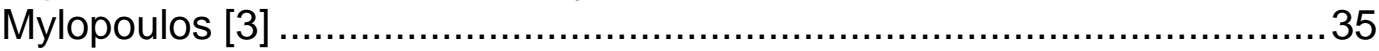

Figura 3.3 - Fluxograma do processo evoluído a partir do processo de

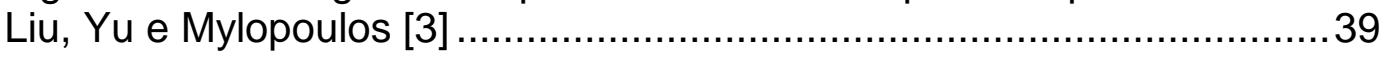

Figura 4.1 - Modelo SD do Expert Committee, reusado de [4] ..................56

Figura 4.2 - Diagrama de SDSituations do Expert Committee,

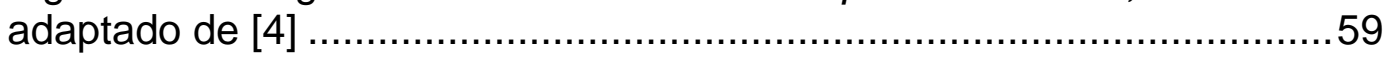

Figura 4.3 - Modelo SD do Expert Committee - versão revisada..............63

Figura 4.4 - Diagrama de SDSituations do Expert Committee,

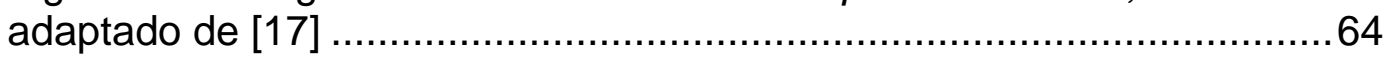

Figura 4.5 - Modelo SA - Atores legítimos ............................................ 72

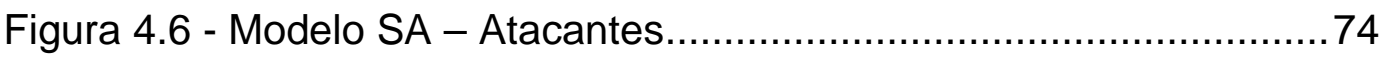

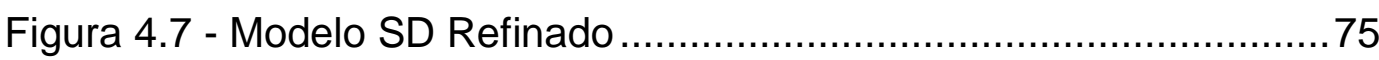

Figura 4.8 - Modelo SR: Researcher x Coodinator................................77

Figura 4.9 - Modelo SR: Conference Organizer (Chair) x Coordinator modelo complementar de [17] ..................................................... 78

Figura 4.10 - Modelo SR: Author x Conference Organizer (Chair) -

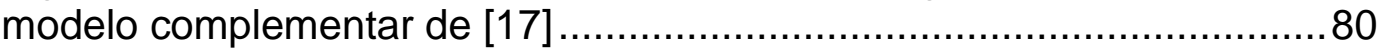

Figura 4.11 - Modelo SR: Reviewer x Conference Organizer (Chair) -

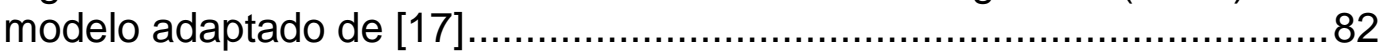

Figura 4.12 - Modelo SR: Conflicts Solver (Committee Member) x Conference Organizer (Chair) - modelo complementar de [17] ................85

Figura 4.13 - Intenções maliciosas dos atacantes internos .......................87

Figura 4.14 - Intenções maliciosas dos atacantes externos ......................88

Figura 4.15 - Tipos de requisitos não-funcionais, baseado em [7] ...........94

Figura 4.16 - Refinamento de segurança por tipo, baseado em [7]..........95

Figura 4.17 - Refinamento de consistência por tópicos............................96

Figura 4.18 - Refinamento de confidencialidade por tópicos.....................96 
Figura 4.19 - Adição de metas flexíveis de segurança às situações de submissão de artigo e recepção de versão final

Figura 4.20 - Adição de metas flexíveis de segurança à situação de revisar artigo.

Figura 4.21 - Adição de metas flexíveis de segurança à situação de resolução de conflito 100

Figura 4.22 - Medidas de ataque dos atacantes externos. 101

Figura 4.23 - Medidas de ataque dos atacantes internos 103

Figura 4.24 - Alternativas de operacionalização para confidencialidade e consistência. 105

Figura 4.25 - Análise de medidas de defesa - confidenciadade interna [artigo revisado] 106

Figura 4.26 - Análise de alternativas: 'usar autenticação com cartão' e 'usar autenticação biométrica'

Figura 4.27 - Análise de alternativas: 'usar senhas múltiplas'................108

Figura 4.28 - Análise de alternativas: 'usar senha simples'....................109

Figura 4.29 - Escolha da alternativa: 'usar senha simples' 110

Figura 4.30 - Análise de medidas de defesa para confidencialidade externa (artigo revisado)

Figura 4.31 - Análise de alternativas: 'usar chave de 64bits' 113

Figura 4.32 - Análise de alternativas: 'usar chave de 128bits' 114

Figura 4.33 - Escolha da alternativa: 'usar chave de 128bits 115

Figura 4.34 - Análise de medidas de defesa para consistência (artigo revisado).

Figura 4.35 - Escolha de alternativa: 'usar mídia de DVD'

Figura 4.36 - Operacionalização de confidencialidade interna e externa e consistência na 'submissão de artigo'

Figura 4.37 - Operacionalização de confidencialidade interna e externa e consistência na 'resolução de conflito' 120

Figura 4.38 - Votação aberta na 'resolução de conflito' 121

Figura 5.1 - Abordagem de casos de uso de segurança, linhas gerais, capturada de [11] 


\section{Lista de Tabelas}

Tabela 4-1 - Identificação de Atores - versão inicial ...........................54

Tabela 4-2 - Identificação de Atacantes - versão inicial .........................55

Tabela 4-3 - Identificação de Atores - versão revisada .........................62

Tabela 4-4 - Identificação de Atacantes - versão revisada ......................62

Tabela 4-5 - Identificação de vulnerabilidades ...................................66

Tabela 5-1 - Resumo de características dos trabalhos analisados .......139

Tabela 6-1 - Rastro do requisito: Segurança do Artigo Revisado...........142 


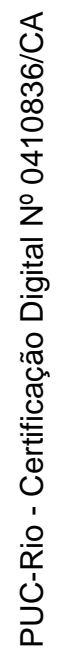

